\title{
FORMAÇÃO DE BOLSISTAS: DIVISÃO TÉCNICO-CIENTÍFICA DE EDUCAÇÃO E ARTE DO MAC-USP
}

\author{
*Maria Angela Serri Francoio, **Andrea A.Amaral S. Biella, ***Evandro Nicolau, ****Sylvio Coutinho
}

\section{RESUMO}

Este artigo apresenta algumas premissas do programa de formação de graduandos da USP enquanto bolsistas na Divisão Técnico-científica de Educação e Arte do Museu de Arte Contemporânea da USP. Os estudantes vivenciam o cotidiano do Museu, participam de programas educativos, recebem formação complementar ao seu curso regular, colaboram com a equipe de educadores no desenvolvimento das ações de extroversão do acervo e adquirem conhecimentos nas áreas da educação e da arte em museus. Provenientes dos cursos de humanidades, os bolsistas exercitam o caráter integrador da instituição museológica dentro da Universidade. Seus relatórios apresentam aspectos da formação no MAC e, trazidos neste artigo, dão voz aos protagonistas dessa experiência.

Palavras-chave: Formação de graduandos. Museu universitário.

\section{ABSTRACT}

This article presents some concepts in undergraduate scholarship at the University of São Paulo (USP) in the Technical Scientific Department of Art and Education of the Museum of Contemporary Art. The scholars experience the museum's daily life and participate in educational programs receiving additional training to their regular course at the university. They collaborate with the education team in developing dialogues with the visitors, focused in the collection. Being from the humanities courses, the scholars exercise the integrating character of the university museum. Their reports point out some training aspects in the MAC and bring out the protagonist's voices according to their experiences.

Key words: Undergraduate scholarship. University museum

\footnotetext{
* Educadora, Mestre, coordenadora da DTCEA desde julho de 2009, coordenadora do Programa Acervo: Roteiros de Visita, ** Educadora, Mestranda na Faculdade de Edudação da USP, coordenadora do Programa Viva Arte!, *** Educador, Mestrando no Programa de Pós-graduação Interunidades Estética e História da Arte, coordenador do Programa Atendimento a Grupos Visitantes no MAC-USP, **** Educador, coordenador do Programa Lazer com Arte para a Terceira Idade.
} 


\section{INTRODUÇÃO}

Este artigo apresenta algumas premissas do programa de formação de graduandos da USP enquanto bolsistas estagiários na área de educação em museus, na Divisão Técnico-científica de Educação e Arte - DTCEA ${ }^{\mathrm{I}}$ do Museu de Arte Contemporânea da USP.

Os estudantes, provenientes das áreas de humanidades, participam de projetos ${ }^{2}$ educativos e acompanham o desenvolvimento de ações para diversos públicos. A vivência no cotidiano da instituição permite-lhes receber formação complementar ao curso regular na USP e adquirir conhecimentos na área da educação e da arte em museus. Dessa forma, exercitam o caráter integrador da instituição museológica na Universidade e colaboram para o cumprimento de uma das funções primordiais da DTCEA, ou seja, a de mediar e adequar os conhecimentos gerados pela pesquisa sobre o acervo e sua consequente extroversão de acordo com o perfil dos visitantes.

No presente trabalho, trataremos de aspectos da formação de um grupo de estudantes, estagiários do MAG USP no período 2007 a 2009. Esses estudantes entraram em contato com o Museu por meio da Coordenadoria de Assistência Social-COSEAS, Programa Bolsa Trabalho que, no ano de 2008, foi substituído pelo Programa Aprender com Cultura e Exten$s a_{0} o^{3}$ da Pró-Reitoria de Cultura e Extensão. O MAC teve, também, o apoio do Fundo de Cultura ${ }^{4}$ da mesma Pró-Reitoria, no período de março de 2008 a fevereiro de 2009.

Os estudantes bolsistas, atualmente, participam dos seguintes programas da DTCEA: Atendimento de Grupos em Visita ao MAC USP, Acervo: Roteiros de Visita, Lazer com Arte para a Terceira Idade e Viva Arte!. Existem outros projetos, programas, cursos e ações da DTGEA que se relacionam com os diversos públicos do Museu, além dos referidos anteriormente, porém, por uma questão

\footnotetext{
I A DTCEA do MAC-USP desenvolve ações de ensino, pesquisa e extensão a partir do estudo do seu acervo e das exposições e eventos organizados pela instituição.

2 Alguns projetos oferecidos à comunidade são configurados como programas permanentes.

3 Carmen S. G. Aranha, Profa. Associada do MAC-USP, foi responsável pela coordenação desse projeto entre agosto de 2008 e junho de 2009 .

4 Idem.
}

metodológica de apresentação de resultados, optamos por tratar em específico dos citados neste parágrafo.

A partir deste foco - formação de estudantes bolsistas e participação nos programas - pretende-se refletir sobre suas experiências no Museu e apresentar resultados qualitativos referentes à complementação universitária que essas bolsas de estágio proporcionam ao estudante. Pretende-se, também, comentar os relatórios produzidos ao final de um ano de estágio pelos estudantes, objetivando mostrar os registros de aspectos da formação no MAC e dar voz aos seus protagonistas.

\section{PROGRAMAS EDUCATIVOS DESENVOLVIDOS NA DTCEA}

Inicialmente serão apresentadas, resumidamente, as propostas de cada um dos programas mencionados, a título de oferecer ao leitor determinados conteúdos que serão citados no decorrer do artigo.

\section{ATENDIMENTO A GRUPOS VISITANTES NO MAC USP ${ }^{5}$}

O MAC é um dos espaços culturais de maior relevância na cidade de São Paulo, cujo acervo é representativo da arte moderna e contemporânea, nacional e internacional. Dada sua importância, há grande procura de visitas agendadas por instituições de perfis diferenciados. O público-alvo do programa é basicamente composto por escolas públicas e particulares dos ensinos fundamental e médio; instituições culturais e universidades e a comunidade em geral.

\section{ACERVO: ROTEIROS DE VISITA}

O programa apresenta material didático desenvolvido na DTCEA com o objetivo de estimular a proximidade de professores e alunos com as obras do acervo do MAC-USP. O material é constituído de pôsteres com reproduções de obras do acervo e fichas didáticas que auxiliam o planejamento, o aproveitamento e o desdobramento das visitas ao Museu. Como parte das ações desse Programa, um curso semestral de difusão cultural é oferecido a professores com o objetivo de fundamentar a exploração desse material

5 Mais informações acerca da fundamentação teórica e pesquisa dos educadores sobre práticas desenvolvidas no MAC-USP podem ser consultadas em artigo de Evandro Nicolau e na dissertação de mestrado de Maria Angela Serri Francoio, constantes das referências bibliográficas. 
e estimular a inclusão do acervo do MAC-USP no planejamento das instituições de ensino. Os participantes vivenciam aulas, oficinas e as exposições, exploram o material didático na instituição onde atuam e visitam o MAC com os seus alunos, norteados por um roteiro de visita elaborado pelo professor como uma das etapas do projeto de ensino da arte. Os trabalhos desenvolvidos durante o curso são apresentados em seminários, possibilitando trocas de experiências e conhecimentos dos resultados obtidos.

\section{LAZER COM ARTE PARA A TERCEIRA IDADE}

Idosos e aposentados interessados em arte contemporânea vêm participando da teoria e da prática da arte no Programa de ateliê Lazer com Arte para a Terceira Idade. A programação é desenvolvida a partir do estudo do acervo do MAC, sendo pioneira em ações regulares para a terceira idade na USP e na Universidade Aberta à Terceira Idade da USP. Durante o acompanhamento nos ateliês os participantes têm uma atualização educacional e cultural em experiências associadas à própria agenda do MAC-USP. O método interativo estimula a criatividade e amplia a inserção no circuito da produção artística contemporânea, além de abrir novos círculos de relacionamentos sociais de referências culturais.

\section{VIVA ARTE! $!^{6}$}

O Programa tem como público-alvo adultos integrantes de oficinas de geração de renda, em instituições sociais, e de oficinas com finalidade terapêutica ocupacional, em instituições de saúde. As atividades visam apresentar o patrimônio cultural da cidade, por meio de visitas a espaços expositivos de diferentes instituições culturais, além do próprio MAG. As aulas são acompanhadas pelos responsáveis das instituições parceiras no intuito de subsidiarem os que necessitam de apoio psicossocial. Como resultado dessa experiência, o participante do Viva Arte! pode ampliar seu repertório cultural e estético referente à produção artística em artes visuais. Integram esse programa cinco instituições da cidade de São Paulo ${ }^{7}$.

6 Veja relato de experiência nos Anais da VII Semana dos Museus da USP.

7 CECCO Ibirapuera (Centro Comunitário e Cooperativa), AMRMC (Associação Minha Rua Minha Casa), CISM (Centro de Integração Social da Mulher), Projeto Roda da Cidadania da Secretaria de Assistência e Desenvolvimento Social da Prefeitura de São Paulo, Projeto Arte que Vem da Rua, da Organização de Auxílio Fraterno, todas elas em São Paulo.

\section{EXPOSIÇÕES, PROGRAMAS E CONTRIBUIÇÕES À FORMAÇÃO DO BOLSISTA}

Embora os programas mencionados no item anterior tenham objetivos específicos, há um eixo de motivação comum a partir das exposições do Museu. Essa abrangência das exposições no campo das ações educativas evidencia a necessidade de uma atuação integrada no Museu, permitindo a construção de um saber cuja estrutura fundamental é interdisciplinar e se apoia no diálogo entre as especificidades dos trabalhos dos diversos setores. Para a DTCEA, preparar uma exposição envolve estudo, pesquisa, encontros com curadores e artistas, discussões em grupo, planejamento de atividades e de materiais didáticos, ou seja, de dinâmicas lúdicas, jogos educativos, oficinas e ateliês, bem como publicações para professores e para o público infantil. A integração favorece a extroversão do acervo ao público visitante, sustentada pelo conjunto de experiências que uma instituição museológica oferece.

O trabalho de formação do estudante compreende o conhecimento e a experimentação das etapas de montagem de uma exposição, dos diversos programas educativos do museu e da análise das referências teóricas e metodológicas pertinentes. O bolsista estuda e pesquisa arte contemporânea, história da arte, questões do ensino e aprendizagem da arte e metodologias específicas da educação em museus de arte. No campo teórico da arte, da educação e da mediação em museus e instituições culturais são examinados autores como Michael Parsons, Ana Mae Barbosa, Abigail Housen, Robert Willian Ott, Paulo Freire, Anne Gauquelin, entre outros. Nesse contexto, o bolsista também é estimulado a trazer os referenciais de sua área de graduação.

Em relação à participação do bolsista nos programas, um conjunto amostral de ações é apresentado a seguir com o sentido de identificar algumas possibilidades na sua formação.

\section{ATENDIMENTO DE GRUPOS EM VISITAS AO MAC-USP}

Tem seu foco de trabalho nas exposições do museu. As atividades de formação são aqui definidas como a realização de visitas educativas a grupos de alunos da educação infantil, a partir de cinco anos, do ensino fundamental e médio das redes de ensino públicas e privadas, e a outros públicos. Cada bolsista 
recebe vinte pessoas por grupo, num período de cerca de noventa minutos, apresentando dialogicamente as exposições do Museu. Para isso, faz contato prévio com os responsáveis pelos grupos agendados, a fim de levantar os objetivos daquela visita, elabora roteiros, define estratégias e avalia o trabalho posteriormente, subsídio que o auxilia na elaboração do relatório final. O bolsista que atua no MAG-USP tem um constante convívio com as pesquisas da cultura artística e a prática pedagógica no espaço expositivo se configura como uma forma de complementar sua formação.

O programa Acervo: Roteiros de Visita ${ }^{8}$ oferece um curso de formação para professores e, entre outras atividades, o estudante bolsista participa de discussões que visam à elaboração de projetos de ensino com ênfase na arte contemporânea e em suas relações com o cotidiano dos alunos na escola; acompanha relatos sobre práticas de ensino e reflexões no sentido de revêlas e transformá-las; o estudante é mediador em visitas orientadas às exposições do MAC para os grupos de educandos desses professores participantes do curso e, assim, ele vivencia essa atividade como uma etapa de trabalho inserida no projeto de ensino da arte.

O programa de ateliê Lazer com Arte para a Terceira Idade oferece ao estudante bolsista a vivência nas diversas linguagens da práxis artística contemporânea: desenho, pintura, gravura, fotografia, colagem, assemblage, modelagem, escultura, instalação, dos multimeios à arte digital. O bolsista desenvolve também, entre outras atividades, o planejamento e organização do ateliê, registra propostas desenvolvidas e ações correlatas, inclusive visitas às exposições do Museu, atividades de dinâmica de grupo, conversas com artistas, programas culturais paralelos, montagem de exposição didática de avaliação, assim como participação das reuniões de avaliação e auxílio na organização de arquivos da memória do programa.

O bolsista participante do Programa Viva Arte! acompanha as ações educativas no contato com grupos de diferentes idades, conhecimentos e necessidades, num exercício constante de convivência que caracteriza a prática inclusiva. O estudante participa da elaboração de planos de aula e de sua frequente atualização. Auxilia na definição de estratégias e recursos materiais

8 As fichas didáticas do Programa Acervo: Roteiros de Visita podem ser consultadas na íntegra no sítio do MAC-USP: www.mac.usp.br, em Projetos. adequados ao público-alvo, dá apoio às relações interpessoais entre os participantes e ao atendimento às necessidades individuais, elabora relatórios, relacionando sua experiência no programa àquela da vida acadêmica. Também registra e organiza as atividades em imagens fixas e móveis e em gravações de áudio.

\section{A VOZ DO ESTUDANTE BOLSISTA ${ }^{9}$}

Os depoimentos a seguir foram extraídos dos relatórios finais e a sua apresentação tem como objetivo destacar a voz do estudante nos aspectos significativos de sua formação durante a vigência das bolsas na DTCEA ${ }^{\mathrm{IO}}$. Nesses trechos, os bolsistas comentam o percurso de estudo, pesquisa e discussão preparatório para ações educativas nas exposições do Museu. A compreensão dos conteúdos da mostra e de sua contextualização a partir de uma visão interdisciplinar são aspectos fundamentais na ação de mediação. Os relatos contemplam premissas teóricas básicas do trabalho e sustentam, durante a prática do estudante, uma postura autônoma de construção de significações para todos envolvidos no processo de atendimento no MAG-USP - o público, os educadores e os estudantes bolsistas.

9 Anita J. L. Rocha Limulja - aluna do curso de Letras da FFLCH, Programa Acervo: Roteiros de Visita, período: março 2008 a fevereiro 2009, Fundo de Cultura e Extensão, PROCEX.

Danilo Bezerra de Souza - aluno do curso de Artes Plásticas na Escola de Comunicações e Artes - ECA, Programa Lazer com Arte para a Terceira Idade, período: agosto 2008 a julho 2009, Aprender com Cultura e Extensão, PROCEX.

Douglas Feitosa Romão - aluno do curso de Filosofia da FFLCH, Programa Atendimento de Grupos em Visita ao MAC-USP, período: agos to 2008 a julho 2009, Aprender com Cultura e Extensão, PROCEX. Guilherme Santos Grise - aluno do curso de Letras da FFLCH, Programa de Atendimento de Grupos em Visita ao MAC-USP, período: agosto 2008 a julho 2009, Aprender com Cultura e Extensão, PROCEX.

Pedro Falcão - aluno do curso de Artes Plásticas, Escola de Comunicações e Artes - ECA-USP, Programa Acervo: Roteiros de Visita, período: agosto 2007 a julho 2008 , Bolsa Trabalho-COSEAS.

IO Vale salientar que os bolsistas Guilherme Santos Grise e Douglas Feitosa Romão apresentaram os trabalhos desenvolvidos no Io. Simpósio Aprender com Cultura e Extensão, em Ribeirão Preto, São Paulo, em setembro de 2009; Danilo Bezerra de Souza apresentou na 6Ia. Reunião Anual da SBPC, em Manaus, Amazônia, em julho de 2009; Anita J. L. Rocha Limulja e Pedro Falcão elaboraram Relatório Final para os períodos de março de 2008 a fevereiro de 2009 , e agosto de 2007 a julho de 2008, respectivamente. 
(...) Arte Brasil Japão - Moderno e Atual - Essa exposição foi importante na minha formação no sentido de romper com o andamento da pesquisa que estava traçando até então, onde todos os artistas e obras anteriores estavam devidamente catalogados e criticados, facilmente acessíveis na biblioteca do MAC. Com essa exposição aconteceu de haver pouco ou quase nada de informações sobre os artistas, o que nos forçou a um campo inseguro, mas ao mesmo tempo em aberto, um tanto quanto alheio às artes ocidentais. Pesquisei sobre o Grupo Seibi (primeira geração de artistas plásticos oriundos do Japão no Brasil), a Segunda Guerra Mundial, os conceitos de alteridade, identidade, miscigenação cultural, religião entre outros. Pude conhecer técnicas como a gravura japonesa ukiyo-e e silk-screen. Pudemos conversar com o artista Mario Ishikawa e com a curadora Elvira Vernaschi. (...)

Anita J. L. Rocha Limulja, Programa Acervo: Roteiros de Visita.

(...) É por isso que, nesse ano de investigação, o corrente projeto visou sempre munir seus orientadores (ou mediadores, preferimos esses termos a monitor) dos conhecimentos e técnicas necessárias para: I) receber seus visitantes de maneira adequada às suas necessidades específicas; 2) estabelecer o diálogo sobre as obras em exposição como meio de proporcionar o conhecimento, imbuindo-o de considerações acadêmicas, conceituais e críticas sempre que instrutivas e interessantes ao grupo; 3) ter domínio sobre o acervo do Museu, sobre as obras em exposição, para possuir a liberdade de se deslocar pelas galerias de maneira independente, responsável e seguindo suas intuições pessoais quanto ao que é mais significativo para si e para seus visitantes.(..)

Guilherme Santos Grise, Programa Atendimentos de Grupos em Visita ao MAC-USP.

No relato abaixo, aspectos da função educativa do MAG-USP são evidenciadas, incluindo a participação do estudante. A repercussão do estágio no cumprimento das disciplinas do curso de graduação se faz, também, a partir da reflexão sobre a teoria e a prática educativa no Museu.

(...) O funcionamento de um Museu universitário como o MAG-USP promove a composição de mais uma parcela do exercício de cidadania. Não menos importante, seu acesso gratuito enrijece a elasticidade do abismo criado entre os estratos sociais na sociedade contemporânea, permitindo a quem seria excluído "naturalmente" nas periferias ou subúrbios o direito ao acesso à cultura. No entanto, ainda na maior parte das vezes não só museus, mas instituições de cultura na cidade de São Paulo restringem-se à região central, quando na melhor das hipóteses ao centro expandido que abarca no limite bairros de classe média. Com efeito, a participação como um estudante de graduação em Filosofia em um projeto de atendimento em visitas agendadas para grupos, em sua maioria da educação fundamental, vem sendo muito satisfatória. Principalmente pelo contato crítico constante com as discussões de práticas educativas e teorias estéticas que contribui para maior eficiência nas disciplinas da graduação.(...)

Douglas Feitosa Romão, Programa Atendimentos de Grupos em Visita ao MAC-USP.

O bolsista localiza fundamentos teóricos para refletir sobre suas observações no estágio, assim como define critérios para análises que envolvam todos os participantes de um programa educativo no recorte do relatório que se segue.

(...) Portanto, hoje, tendo maior conhecimento do que é a "observação participante" na antropologia cabe pontuar que esse tópico não descreve bem a metodologia real, embora, no momento em que a escrevemos (abril/ maio de 2009) tenha nos parecido a mais apropriada. Acho que uma melhor forma de refletir e avaliar a metodologia do Programa LAPTI seria confrontá-la com interpretações da abordagem triangular (nos escritos de Ana Mae) estabelecer uma estratégia de recolher "devolutivas" dos educandos, educador e estagiários e analisar comparando os resultados 
reais (satisfação, exposição, expectativa, frequência, laços, desenvolvimento) focando a experiência significativa [Rejane Coutinho]. E assim apontar "adequações”, "inadequaçõe”, “inovações”, "desvios”, etc.(...).

Danilo Bezerra de Souza, Programa Lazer com Arte para a Terceira Idade.

A oportunidade de integração dos bolsistas com professores das redes de ensino na elaboração de projetos educativos e a aproximação com a realidade da escola pública, são aspectos pontuados no relatório, do qual foi extraído o relato que se segue.

(...) Os benefícios da integração com os professores são muitos - dada a situação de que sou graduando de licenciatura em artes plásticas. A chance de eu poder conhecer, opinar e interferir - no que diz respeito à construção e concepção sobre os projetos desenvolvidos pelos professores participantes deste curso em suas respectivas escolas, o que me dá a oportunidade de familiarização com uma diversidade muito grande de métodos e situações vividas no ambiente escolar. São projetos de arte-educação que têm, como base, a utilização dos materiais de apoio do MAC, contendo propostas e sugestões para o ensino da arte, e, a partir disso, a gama de ideias provenientes e passíveis de execução é extraordinariamente grande. (...)

Pedro Falcão, Programa Acervo: Roteiros de Visita

Os depoimentos seguintes referem-se a uma dinâmica de integração entre bolsistas e educadores a partir das vivências nos programas na DTCEA.

(...) Através da Divisão Técnico-científica de Educação e Arte do MAG-USP empreende-se ações capazes de contribuir com a transformação de certas condições socioculturais através de atividades educativas ligadas ou não às exposições. Na sede MAC Ibirapuera, dentre outros, são realizados os programas Interar-te (integração entre as faixas etárias e públicos - familiares ou amigos - através de atividades lúdicas motivadas pelas exposições em car- taz), Viva Arte! (programa de inclusão socioeducativa e cultural), Encontros Contemporâneos (encontros com artistas e curadores visando a formação continuada de educadores), além das visitas agendadas (mediação de grupos em geral escolares). Dentro dessas concepções de aproximação de um museu de arte e público explorou-se discussões de formação entre a equipe sobre a inter-relação de estética, história da arte, crítica de arte e fazer artístico. Entendeu-se que por colocar ao alcance da fruição da comunidade uma exposição, a educação em museus tem papel de extrema importância e não só como apêndice das intenções do curador. O educador deve ter preocupações com teoria e dimensão estética que se complementam com as atividades curatoriais, mas sobretudo aproximar-se das experiências anteriores do público.(...)”

Douglas Feitosa Romão, Programa Atendimentos de Grupos em Visita ao MAC-USP.

(...) Juntamente com a educadora Maria Angela Serri Francoio pude iniciar um processo contínuo de ensino-aprendizagem com dois alunos do Ensino Médio participantes do Programa Pré-iniciação Científica USP, da Pró-reitoria de Pesquisa. Temos pesquisado diversos assuntos sobre arte e cultura. Visitamos diferentes instituições, dentro e fora da USP, como o Cinusp, o Museu de Arqueologia e Etnologia, Paço das Artes, Museu da Língua Portuguesa e Instituto Tomie Ohtake (...).

Anita J. L. Rocha Limulja

(...) Tenho a oportunidade de ouvir outros educadores da Divisão em suas participações no Programa, quando apresentam a maneira como desenvolvem seus projetos, como aconteceu com a Profa. Carmen Aranha e o educador Evandro C. Nicolau, curadores da atual exposição "Conexões", e com o educador Sylvio Coutinho, que nos colocou mais próximo do processo de montagem da sua exposição corrente no MAC Anexo, com trabalhos de seus alunos, e como foram desenvolvidas as suas aulas. (...).

Pedro Falcão, Programa Acervo: Roteiros de Visita. 


\section{ALGUMAS CONSIDERAÇÕES FINAIS}

Os museus de arte são espaços culturais privilegiados para a complementação curricular do estudante bolsista e o sentido dessa experiência de estágio se amplia com a compreensão de que a arte é conhecimento e seu ensino oferece a oportunidade de integrá-la a outras disciplinas do saber. Nesse sentido, os graduandos, dentro de suas formações diversificadas, são favorecidos e enriquecem a relação de diálogos e trocas humanas que se pretende estabelecer entre o público e o educador a partir do acervo do MAC.

$\mathrm{O}$ acesso a esse acervo pode ser ampliado por meio de ações educativas integradoras e o trabalho de formação dos bolsistas colabora para esse fim. Deve-se considerar que o estágio é também uma experiência de profissionalização.

Ao recolher algumas indicações presentes nos textos dos estudantes sobre a formação no MAC, nota-se que as contribuições dos programas da Divisão Técnico-científica de Educação e Arte do MAG-USP são relevantes na sua formação. Coloca-se dessa maneira, em evidência, a importância do apoio das PróReitorias às ações de extensão à comunidade que repercutem na pesquisa e no ensino, tornando possível o caráter integrador dos museus na Universidade.

\section{AGRADECIMENTOS}

Aos colegas da DTCEA e, em especial, à Profa. Dra. Carmen Aranha, que acompanhou a elaboração deste texto.

\section{REFERÊNCIAS BIBLIOGRÁFICAS}

BARBOSA, A. M., org. O ensino das artes nas Universidades. São Paulo: Edusp, I993.

BIELLA, A. A. A. S. Programa Viva Arte! do Museu de Arte Contemporânea da USP - Relato de uma Experiência Educativa em Fase de Avaliação. In: Semana de Museus, VII, São Paulo: CPC-USP, 2009.

GAUQUELIN, A. Arte Contemporânea: Uma introdução. São Paulo: Martins Fontes, 2005.

FREIRE, P. Pedagogia da Autonomia: saberes necessários à prática educativa. São Paulo: Paz e Terra, I996.

FRANCOIO, M. A. S. Museu de Arte e Ação Educativa: Proposta de uma Metodologia Lúdica, Dissertação de Mestrado, São Paulo: ECA-USP, 2000.

NICOLAU, E. C. Exposição de arte e recepção educativa do público. In: Coelho, R, org. Concepção_de Projetos para Montagem de exposições de Arte - Caderno de Experiências. São Paulo: SENAC, 2007, p. 73-82.

OTT, R. Ensinando Crítica nos Museus. In: BARBOSA, A. M. org. Arte-Educação: leitura no subsolo. São Paulo: Cortez, I997.

PARSONS, M. J. Compreender a arte: uma abordagem à experiência estética do ponto de vista do desenvolvimento cognitivo. Lisboa: Presença, I992. 